\title{
Assessment of Environmental Impact of Production Processes in Industrial Districts Using Input-output Modeling Techniques
}

\author{
V. Albino ${ }^{1}$ and S. Kühtz ${ }^{2 *}$ \\ ${ }^{1}$ DIMEG, Politecnico di Bari, 182 Viale Japigia, Bari 70126, Italy \\ ${ }^{2}$ DIFA, Università della Basilicata, Cda Macchia Romana, Potenza 85100 , Italy
}

\begin{abstract}
An industrial district is a group of firms housed in a limited geographic area and specialized in one or more stages of a given production cycle. The concentration of firms in a limited area characterizes unique environmental problems in conjunction with local communities that need to be carefully assessed. This paper presents an assessment of the environmental impact of industrial districts that is carried out using an input-output accounting model in connection to relevant materials and energy flows within an industrial district. Resources used, wastes produced and energy consumed in the system of concern are quantified by the input-output accounting model to provide invaluable information for both private and public managers leading to meet the sustainable development goals in local communities. Also, information for screening the technologies in conjunction with recycling, re-use, and recovery strategies can be drawn. Two case examples, related to the Italian industrial districts of Sassuolo and Matera, in North and South Italy, have been analyzed using such input-output accounting model as a tool.
\end{abstract}

Keywords: Input-output techniques, enterprise input-output, industrial district, environmental assessment

\section{Introduction}

Clusters are geographic concentrations of interconnected firms and institutions operating in a particular economic field. In the globalization era they remain competitive industrial systems throughout various geographic, cultural, and institutional proximity. This kind of economic impact has been widely recognized by many developing and developed countries around the world (OECD, 2000; Porter, 1998). Clusters provide companies with special access, closer relationships, better information, powerful incentives, and other advantages that are difficult to get from a distance.

As pointed out by the Organization for Economic Co-operation and Development (OECD 2000), clusters of firms and inter-firm networks seem suitable to enhance the competitiveness of small and medium enterprises in the global economy. In particular, firms that operate in related lines of business are generally located in physically close proximity. So location remains critical in terms of competition in local business and turns out to be a dominant force that shapes regional economic development. Clusters are now widespread in developed and developing countries and different size, technological level, and network organization characterize different cluster models (Becattini et al., 1992; Piore and Sabel, 1984; Shridharan and Manimala, 1999). Indeed, cluster

\footnotetext{
* Corresponding author: kuhtz@unibas.it
}

development policies have proliferated in central and peripheral regions of many metropolitan areas with changing and versatile philosophies in response to the role of economic development in government agency. An industrial cluster can contain a small or large number of enterprises, as well as small and large firms in different proportions. Clusters have been studied by early regional development literature (Isard and Vietorisz 1955; Isard et al. 1959) and analysed since then with input-output matrices (Isard and Schooler, 1959). Clusters and networks can allow small firms to combine advantages of small scale with several of the benefits of large scale. Then, membership of clusters and networks can enhance the productivity, rate of innovation and competitive performance of firms (OECD, 2000). Some clusters, such as Silicon Valley, are characterized mainly by technology-based companies that collaborate with local institutions such as universities (Saxenian, 1999). Other clusters, such as many of Italy's industrial districts, are comprised principally of small and medium enterprises. Unfortunately, even in advanced economies, this kind of cluster pattern of economic geography can deteriorate the local quality of life as a result of higher environmental impact because of its centralized pattern.

The successful operation of some classical industrial districts (ID) is becoming an exemplary model in economic development. They are normally characterized by an agglomeration of small and medium-sized firms located in a specific geographic area and specialized on one or more phases of a production process (Becattini, 1989). 
Nowadays sustainability concept is important for economic development policies at both global and local levels. Since the question about the integration between production and environmental systems has become a focus for making local development policy, many studies were carried out to investigate the environmental impact of production systems. Some of these studies are focused on industrial districts (Albino et al., 2003; Ambiente Italia, 2000; Ambiente Italia, 2001; Borghini and Cibin, 1999). As Marshall (1920) affirms, there is a great symbiosis between industrial and social system within the district. This happens because the firms are localized within the urban system as well as because the local community represents the workforce and assists management of the firms. So, attention has been driven to force the stakeholders of these production systems to take into account environmental aspects. These pressures are due to the strong integration with the socio-institutional context of such production systems and the strategic reasons and law compliance needs of district stakeholders. A study on three Italian districts (glass, stone and chair districts) localized in the Veneto region highlighted that the district firms are pushed by two different kinds of pressure, including external pressures (i.e., regulation, local community, environmental associations, opinion groups) and internal ones (i.e., supply chain stakeholders) (Borghini and Cibin, 1999).

In order to take into account the environmental impact in connection with performed activities in those clusters, conducting a systems analysis with respect to overall production processes in conjunction with environmental impacts is necessary in each district. Also, being an important part of sustainable development strategies in which material and energy efficiency is emphasized and aimed at changing and reducing material flows and pollution in totality, goods production and exchange programs along the supply chain within the district have to be considered (Nathani, 2000). Then, the supply chain approach can be used to analyze the environmental impact of an industrial district based on a systematic way. In particular, the extended supply chain approach seems particularly suitable to analyze the environmental aspects of an ID. The extended supply chain concept rises from the extension of supply chain boundaries to the inclusion of the source and the destination of all the physical material flows used and produced at each supply chain stage (Beamon, 1999a). This could become part of the life cycle assessment (LCA). Input-output modeling techniques have been proposed for economic-energy-environment analyses using material and energy flow data related to those supply chains (Albino et al., 2002), and to the associated IDs (Albino et al., 2003). To achieve this goal, it requires collecting essential data on-site in a rigorous way.

The assessment of the environmental impact of IDs in this paper is performed based on an extension of the input-output accounting model proposed by Albino et al. (2003). Different product families within a district are considered, and real data from the field (i.e. data from two different Italian industrial districts) are collected. The production network of industrial districts is modeled in terms of production processes and material/energy flows. The input-output accounting model allows estimation of resource (materials and energy) use and the subsequent pollution emissions and the environmental impact of an industrial district are therefore assessed for providing the apprehensive understanding in the context of sustainability in a regional sense.

\section{Main Features of Industrial Districts}

As defined by Porter (1998), clusters encompass an array of linked industries and other entities important for competition. They include, for example, suppliers of specialized inputs such as components, machinery, and services, and providers of specialized infrastructure. Clusters often vertically dispense downstream product to distribution channels and customers and laterally aid in other manufacturers through providing complementary products and/or other companies in industries through offering related skills, technologies, and necessary inputs. Many clusters even involve the direct linkage with different institutions such as universities, standards-setting agencies, and trade associations.

Some features of clusters may help characterize industrial districts. Some studies (Becattini et al., 1992; Piore and Sabel, 1984) referred to those successful industrial districts as the "Third Italy" intensively. These districts consist of groups of firms producing textiles, knitwear, shoes, leather products, furniture, tiles, musical instruments, food, mechanical-engineering products, etc. They are characterized by the presence of some features: firm size distribution, up- and downstream industrial linkages, degree of vertical disintegration, networks among district firms, district wide governance structures, innovative capabilities and the organization of production.

Though there are variations in experiences, industrial districts are an important feature of other countries too, in Europe (such as Germany, France, Belgium, and Denmark) as well as in Asia (such as India, Korea, and Taiwan). In recent years, the success of industrial clusters in "Third Italy" with concentration of small and medium enterprises has brought this phenomenon into attention as a viable alternative approach to industrialization. Small firm clusters have come to occupy a significant space in the discussions on industrialization strategies, especially in the context of less-developed regions (Shridharan and Manimala, 1999).

However, Storper and Harrison (1991) opt for an expansive connotation of industrial district, which does not confine it to the most common usage, denoted by Marshallian (or Italianate variant) district. Similarly, Markusen (1996) defines an industrial district as a sizable and spatially delimited area of trade-oriented economic activity that has a distinctive economic specialization of resource-related, manufacturing, or services features. Then, 
Markusen (1996) rejects the term "new industrial district", in either its Marshallian or more recent Italianate form, as the dominant paradigmatic solution, and identifies three additional types of industrial districts, with quite disparate firm configurations, internal versus external orientations, and governance structures: a hub-and-spoke industrial district, revolving around one or more dominant, externally oriented firms; a satellite platform, an assemblage of unconnected branch plants embedded in external organization links; and the state-anchored district, focused on one or more public-sector institutions. The hub-and-spoke and satellite platform variants are argued to be more prominent in the United States than the other two.

Although the presence of Marshallian industrial districts, even the Italianate version, can be confirmed in a number of American instances, in the United States most rapidly growing industrial regions do not exhibit the same characteristics as those in the Third Italy. Even Silicon Valley is more a mix of industrial district types than a typical case of Italianate industrial district (Markusen, 1996). Sometimes, the concept of technological cluster (or technological district) has been applied to the analysis of localized socio-professional dynamics in a context of rapidly changing technological and economic opportunities. In this case, industrial technological background (and particularly local expertise and know-how) represents the basis for optimal adaptability to the market (Loinger and Peyrache, 1988). Moreover, while certain regions have been able to innovate giving priority to knowledge transmission based on the exchange of brainpower or the direct exchange of process technology, it should be remembered that there is also the classic form of exchanging technical know-how as the direct product of normal inter-enterprise market relations (Aydalot, 1988) or of socialization (Becattini et al., 1992).

However, as recognized by many scholars, the industrial district is not an analytical model, but rather a list of stylized facts useful to define an ideal-typical industrial district. From the ideal type arisen from the Italian experience, four key factors characterizing industrial districts emerged (Rabellotti, 1995). They are:

- clusters of mainly small and medium-sized enterprises spatially aggregated and sectorally specialized;

- a set of forward and backward linkages, based both on market and non-market exchanges of goods, knowledge, and people;

- a common cultural and social background linking economic agents and creating a behavioral code, sometimes explicit but often implicit;

- a network of public and private local institutions supporting the economic agents acting within the cluster.

High flexibility and specialization characterize the production process within the district:

- flexibility is obtained through "special" relationships in the labor market: intensive use of home workers and availability to work extra hours, allowing fast and easy adaptation of the labor force to be able to react to demand changes;

- $\quad$ specialization is due to the division by phases of the production process, allowing a more efficient exploitation of the different economies of scale and a higher innovation capability than in vertically integrated firms.

Non-competitive relationships among firms are assumed because small enterprises may have to collaborate with each other in order to respond to large orders. Also, collaboration can take place between specialized firms in the different phases of the production process and between producers and technology suppliers. Unlike the passivity of Marshall's firms, Italianate districts exhibit frequent and intensive exchanges of personnel between customers and suppliers and cooperation among competitor firms to share risk, stabilize markets, and share innovation (Markusen, 1996). Further, the role of family is also emphasized in some cases because it contributes to ease labor force allocation and to render a low-cost system of reproduction and circulation of technical and managerial knowledge within the district. Beyond the family scale, a common social origin and, in some cases, political homogeneity also in favor of collaborative relationship, being characterized by intensive face-to-face contacts, sharing of values, behaviors, codes, and languages (Bagnasco, 1988).

\section{Industrial Districts and Environmental Issues}

As recognized by Renn et al. (1998), there is a public conviction that a political region within a country is an appropriate arena for public and private debate and decision-making on sustainable development. Work within a region offers the best practical hope at this time for developing effective political agreement on the concept of sustainable development and on operations in support of that concept. Based on such understanding, a region can most efficiently put into effective measures for sustainable development. Regions have several advantages over both larger political units (nations and international agreements) and small units (such as cities). Among these advantages, a region offers reasonable homogeneity in population characteristics, in economic practices, and in the configuration of the environment. To be realistic, approaches to sustainability must make good ecological sense and be politically and economically feasible, and both aspects are best pursued within the confines of a region. Also, regions generally have suitable political institutions and regulatory mechanisms for legitimizing sustainability in their state charters, and to implement effective actions. Regions are also a preferable focus of implementation because of the opportunities provided for experimentation, competition, exchange of information, and mutual learning. Similar regions can develop their own approaches and share experiences with one another. 
Such efforts will encourage adaptation and evolution in developing solutions to typical problems. However, each region has its specificity and the implementation of sustainable development has to be tailored on this specificity. For instance, pollution levels that are not acceptable in one region can be acceptable in another region if employment needs are more crucial.

Local public administrations and firms are considering the relevance of sustainable development in order to combine production and environmental urges. Local areas competitiveness/attractiveness is in fact based on a balance between economic and eco-system issues and more and more managers realize that a focus on sustainability can provide strong returns while also meeting the human needs and reducing the environmental footprint of their operations (de Bruijn and Hofman, 2001; Holliday, 2001). Of course, managers do not share this opinion. Some of them think that corporate sustainability won't occur (Schendler, 2002).

At the industrial district level, small-medium size autonomous enterprises, strongly concentrated in a limited geographic area, are related to the environment by intensive material exchanges. Monitoring and planning production activities at system level can be useful for an effective improvement in production/recycling/consumption patterns eventually resulting in mutual benefits for enterprises and local environment. Then, there are some factors that make the relationship critical between an ID and its environment.

First, the concentration of a large number of firms within a limited geographic area amplifies the negative impact produced on the environment by production systems. In fact, the use of resources and the production of pollution are concentrated in a limited space. Second, the production's organization in an ID (flexible specialization) is generally distributed among a multitude of small firms. Then, the interaction between production processes and environment is distributed and not concentrated as is in the case of few large firms. For instance, components and products have to be moved inside the area as well as wastes have to be collected for reuse, recycling, and recovery, or ortherwise for final disposal. Transportation is then required and this increases pollution and congestion problems. Third, the firms' dimension of IDs has also some direct implication on the environment. Hamner and Del Rosario (1997) explained that there are three main reasons that the small and medium-sized firms are of particular concern for environmental protection:

- $\quad$ since they have generally less capital, investments in pollution control are less affordable;

- $\quad$ since they are large in number and low in individual visibility, governments have a difficult time in monitoring them;

- $\quad$ since they are often located in highly urbanized areas, the impact of their pollution on human health can be serious and immediate.

From the point of view of firms belonging to an ID, inside and outside pressures are forcing them to take into account and to improve the environmental performance. Inside pressures are motivated by strategic reasons. In fact, ID firms are becoming aware that improving the environmental performance can result in both economic and environmental benefits. Outside pressure is also due to the strong relationship between the socio-institutional context and the production system. In order to analyze, in a systematic way, the environmental aspects involved in the activities performed by ID firms, the concept of a supply chain has been considered.

The supply chain represents an integrated process wherein a number of various business entities (i.e. suppliers, manufacturers, distributors, and retailers) work together to acquire raw materials, convert them into specified final products, and deliver final products to retailers (Polenske, 2001). The ID supply chains present some specific characteristics. Different firms, localized in the district area, work together to produce and deliver final products to market. Usually, production processes are performed by different firms, each of them concentrated on one or more production phases. The same phase of the ID is generally performed by several firms. However, firms performing the same phase in an ID are usually characterized by similar organizations and technologies. In fact, imitation is one of the most effective sources of innovation in the ID (Albino et al., 2000). Some phases can be realized outside the ID. The supply chains within the district can be considered to take into account the impact of production processes on the local environment. Some insights about how to incorporate environmental issues when analyzing industrial supply chains have been analyzed by some authors (see, for instance, Barry et al., 1993; Bloemhof-Ruwaard et al. 1995).

However, for a more complete evaluation of the interaction between production and environmental systems, the whole supply chain structure has to be redefined and all the productive process and product effects on the environment need to be considered, from the raw materials extraction process to the used product disposal (Beamon, 1999b). The idea to extend the supply chain (extended supply chain) starts from the redefinition of the supply chain, to realize the operational and environmental integration, considering the growing complexity due to the firm product/process realization/execution (Beamon, 1999a). Then, the extended supply chain is a descriptive model which comes out of the supply chain boundary extension to include, beside the flows exchanged among the firms involved in the same supply chain, also those which come from and go towards the environment. The extended supply chain includes all the recovery mechanisms of products/by-products and it provides, in each supply chain stage, a destination for all physical flows both of final products and by-products. Then, the extended supply chain approach allows the environmental performance of the network of interdependent firms of an ID to be analyzed in a systemic way. 
To quantify the interactions between production and environment systems along the extended supply chains, an interesting approach, used for managerial accounting at enterprise (corporation) level is based on input-output accounts (Polenske, 1997). Different benefits can be associated with this approach: physical and value accounts can be included; data on production units and plants are systematically collected and arranged in an information system; production targets can be defined and planning activities carried out, and a link to input-output accounts for more aggregated economic systems (such as industrial sector, geographic region, entire nation, etc.) can be obtained building relationships between micro and macro analysis level. This approach has been proposed for the analysis of materials and energy flows within an industrial district (Albino et al., 2003).

\section{Environmental Impact}

As a consequence of the introduction in the public opinion of concepts such as sustainable development and green manufacturing, the need to measure and compare economic, social and technical systems has increased. Different environmental performance indicators are now available in the literature and used in actual cases (see, for instance, WEF, 2001). All these indicators try to catch specific aspects of the analyzed system (company, companies network, region, country, etc.). In fact, it is hard to define indicators that are able to integrate all the economic, social and technical aspects, and their relationships with the environment, as well as to define the appropriate physical limits of the analysis. For instance, community health, social justice, business vitality, energy saving and environment pollution must be considered jointly to get a fare measure of sustainability. Also, production activities can have different size and place of impact on the environment because of interdependency. However, at the same time, specific indicators can support public and private managers to monitor systems and to make decisions, as well as the community to increase its awareness.

The Lowell Center for Sustainable Production (LCSP) (Veleva et al., 2001) provides some guidelines to develop a suitable approach to the use of indicators. Five levels of indicators are suggested. Three levels concern company performance (comply with law, use of materials, effects on environment and health). The fourth level includes the supply chain and the life cycle of products, and the fifth level considers the global effect of company activities in terms of sustainable development. At the company level, company-specific environmental indicator systems have been proposed to plan, steer, and control environmental strain, performance and costs (Jasch, 2000). Comparing indicators for different years, sites or firms (benchmarking) allows for the evaluation of progress and potential savings within a firm's environmental program. Similar indicators can be proposed for industrial districts but systematic measures of the impact of all production processes on the environment performed by district firms are required. In fact, local policies have to consider the strong interactions along the supply chains being characterized for a specific firm or process that is able to generate direct and indirect impact on other processes and firms.

Ecological footprint analysis is another methodology that aims to represent simply, and communicate effectively, issues of environmental impact and sustainability. It allows for the aggregation of a range of impacts into a single indicator. It therefore facilitates the comparison of different types of environmental loads. The indicator commonly used is based on the concept of appropriated carrying capacity, defined as the amount of land required to supply the necessary resources and to assimilate the outgoing wastes. So, referring to an individual, the ecological footprint is defined as the amount of land required to support one person's consumption and waste production. This measure can be helpful to evaluate if human being's consumption of the natural resources, has exceeded the regenerative capacity of the earth. In fact, the ecological footprint is the corresponding area of productive land and aquatic ecosystems required to produce the resources used, and to assimilate the wastes produced by a defined population at a specified material standard of living, wherever on earth that land may be located (Wackernagel and Rees, 1996). Clearly environmental footprint analysis needs to be supplemented by the use of other measures to account for human welfare. In fact, van den Bergh and Verbruggen (1999) underline that environmental footprint analysis does not provide sufficient information on environmental impact and on a regional level it can be easily misinterpreted as it is a measure extremely aggregated and that makes no distinction between sustainable and unsustainable land use.

In this paper, the concept of environmental impact considered for an ID is configured based on the quantitative measures of all the resources used (materials, including water, and energy) and all the intermediate outputs and wastes produced to produce the final products destined to the market. This impact can be referred to the local or global environment if local or global resource consumption and wastes production are considered, respectively. Then, for each unit of product sold to the market the local or global environmental impacts are the quantity of resources used and of wastes produced inside the district or wherever those resources are used and wastes produced, respectively. Similarly, the ID environmental impact can be defined for the total amount of products an ID can produce in a given period of time, for instance a day or a year. This measure aggregates all the impacts generated by all the production processes required to make products. This allows simple evaluation of different development policies at the ID level: for instance, balancing the increase of production level caused by increased demand, and the reduction of waste product unit maintaining a constant ID environmental impact. The environmental impact defined for the industrial district as a whole can be also applied to each firm in the district, can be used to compare the environmental behavior of each firm within 
the industrial district. Besides, benchmarking based on environmental impact is possible.

\section{Assessment of Environmental Impact Using an Input-Output Model}

The measure of the environmental impacts of an industrial district can be based on the input-output accounting model proposed for the economic- energy-environment analysis of an industrial district (Albino et al., 2003). This model is based on an input-output table that gathers materials and energy flows data related to the production processes of the district, and allows quantify resource use and consequent pollution emissions. Flows of materials and energy, measured in physical terms, are inputs and outputs of processes composing the supply chains within the industrial district. A production process is considered as a function that transforms inputs (resources including energy) into outputs (wastes, by-products and product) (Figure 1).

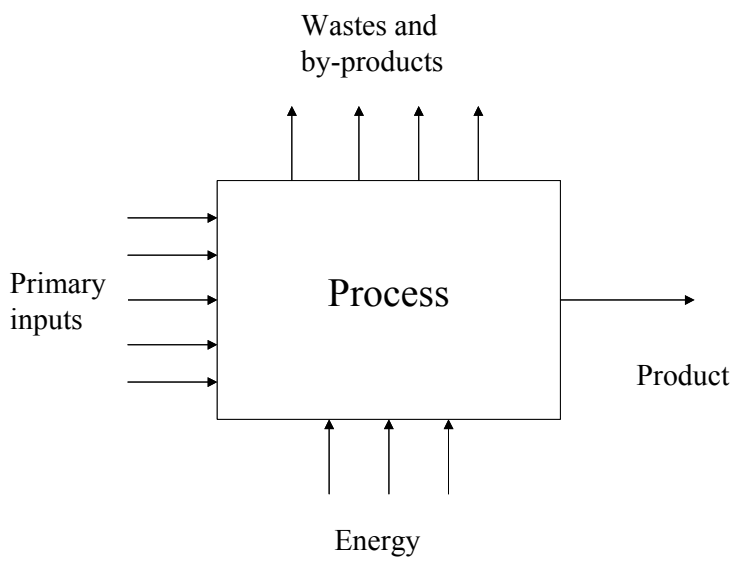

Figure 1. Production process representation.

Processes are assumed to have one specific product or a homogeneous group of products as their main output. In the case of co-production (two products belonging to two different groups), it is assumed that a process can be split with a proper allocation of inputs and outputs. The aggregation level of processes can be freely chosen according to the aim and aggregation level of the analysis. A supply chain is a network of interrelated production processes that procure raw materials, transform them into intermediate products and then the end product (or homogeneous group of end products), and delivers intermediate and end products to customers through a distribution system. Then, a supply chain is a production process network whose final products are (intermediate and end) products that are destined outside the supply chain. Each supply chain within an industrial district can be built if all the production processes are traced starting from the last process of the chain producing a final product.
Let us consider the supply chains within a district having the same end product (or end products belonging to the same homogeneous group) of the last process. Many processes belonging to different firms (or also to different production units of the same firm) are characterized by similar organization and technology doing the same phase of the production cycle of the end product. So, a district production process network (DPPN) can be defined. Each process of the DPPN is an aggregated process whose inputs and outputs are the sum of inputs and outputs, respectively, of all the processes that in the district are similar for the type of technology adopted and the main output produced. Let us consider an industrial district. The main output of a district process (DP) is the input of the next district process, and the end product is the main output of the last one. Each DP requires a given quantity and type of energy (i.e., electric energy, solid, liquid, and gaseous fuels) as input. By-products and wastes are also considered as outputs for each DP. An industrial district can be characterized by a single end product (i.e., leather sofas, although they can be different in style), similar end products (family) (i.e., cutlery: knifes and forks undergo some different processes; sofas, leather or fabric) or more than a family (cutlery and kitchenware undergo completely different processes).

In particular, to distinguish a family of products it is possible to operate as follows: if the supply chains relative to two different end products have at least one process in common they can be considered a family and their supply chains are lumped. If this happens in just one or few firms of the sample considered it may be better to leave the supply chains separated; however this is left to the judgment of the researcher involved because it depends on the homogeneity of the products considered. Then, each DPPN is associated with an end product (or its family).

Let us consider for each DPPN the model proposed in Albino et al. (2003) resulting in the following equations:

$$
\begin{aligned}
& x=(I-A)^{-1} f \\
& r=R x \\
& e^{d}=E x \\
& w=W x \\
& e^{s}=T w
\end{aligned}
$$

where the matrix notation indicates:

$x=\left[x_{i}\right]=$ vector of the gross output;

$f=\left[f_{i}\right]=$ vector of the final demand (deliveries leaving the industrial district);

$r=\left[r_{k}\right]=$ vector of the primary input;

$e^{d}=\left[e_{k}^{d}\right]=$ vector of the energy demand;

$w=\left[w_{k}\right]=$ vector of by-product or waste;

$e^{s}=\left[e_{k}^{s}\right]=$ vector that indicates the amount of energy produced by waste-energy transformation (using only waste produced in the district); 
$I=\left[I_{i j}\right]=$ identity matrix;

$A=\left[A_{i j}\right]=$ matrix of intermediate input-output coefficients (i.e. output of product i per unit of output of product $j$ );

$R=\left[R_{k \mathrm{j}}\right]=$ matrix of primary input coefficients (i.e. primary input of type $\mathrm{k}$ per unit of output of product $\mathrm{j}$ );

$E=\left[E_{k j}\right]=$ matrix of energy input coefficients (i.e. input of energy of type k per unit of output of product $\mathrm{j}$ );

$W=\left[W_{k j}\right]=$ matrix of waste output coefficients (i.e. output of by-product or waste of type k per unit of output of product $\mathrm{j}$ );

$T=\left[T_{k h}\right]=$ matrix of waste-energy transformation coefficients (i.e. amount of energy of type produced per unit of waste of type $h$ ).

Each process belonging to a DPPN can be modeled by the technical coefficients, assumed constant in the short-run. In order to estimate technical coefficients, statistical data collection for each production process has to be based on the sample of similar processes producing the same product $\mathrm{j}$ or energy of type $\mathrm{k}$. These similar processes generally are performed by different firms but a firm can have two or more processes producing the same product $\mathrm{j}$ or energy of type $\mathrm{k}$ in different production units or, also, in the same production unit.

Some guidelines for statistical estimation can be provided. The main data sources can be official and industry statistics for production, foreign trade, consumption, and amount of waste. Specific data concerning process inputs and outputs are based on technology-specific data like process descriptions, material and energy flow analysis of the production and interviews with technology experts (common in ID). An important and time-consuming work is the harmonization of these data sources with regard to divergent technological states-of-the-art, different base years or levels of representativeness, and the estimation of missing data. Moreover, as said before, each process can be assumed as a function that transforms inputs into outputs and depends on technology and organization adopted for the transformation.

In an industrial district each process that operates the same phase is similar for the following reasons. Firms are similar for size and then they can adopt similar technology and organization. Physical proximity, non-competitive relationships and the social networks favor imitation of process technology and organization. As a consequence, a small variation can be observed in the technical coefficients. So the sample size can be small due to the similarity of processes performing the same phase. However, sometimes, some variations in organization and technology adopted by a firm can be observed. This can happen, for instance, if a leader (usually larger) firm is located in the industrial district. Processes performed by leader firms are usually more efficient. They can be assumed as the reference (benchmark) within the district, as they are usually imitated by smaller firms.
For all these reasons, a weighted average estimation of technical coefficients for similar processes is recommended where process outputs are weights. Then, for a PPN and for the generic DP producing product $\mathrm{j}$, technical coefficients are estimated using the weighted average over the technical coefficients of $\mathrm{m}_{\mathrm{j}}$ similar processes:

$$
\begin{aligned}
& A_{i j}=\sum_{u=1}^{m_{j}} x_{j}^{(u)} A_{i j}^{(u)} / \sum_{u=1}^{m_{j}} x_{j}^{(u)} \\
& R_{k j}=\sum_{u=1}^{m_{j}} x_{j}^{(u)} R_{k j}^{(u)} / \sum_{u=1}^{m_{j}} x_{j}^{(u)} \\
& E_{k j}=\sum_{u=1}^{m_{j}} x_{j}^{(u)} E_{k j}^{(u)} / \sum_{u=1}^{m_{j}} x_{j}^{(u)} \\
& W_{k j}=\sum_{u=1}^{m_{j}} x_{j}^{(u)} W_{k j}^{(u)} / \sum_{u=1}^{m_{j}} x_{j}^{(u)}
\end{aligned}
$$

For the generic DP producing energy of type k using waste of type h, it results:

$T_{k h}=\sum_{u=1}^{m^{\prime} k h} x_{j}^{(u)} T_{k h}^{(u)}$

being $\mathrm{m}_{\mathrm{kh}}$ the number of processes converting waste of type $\mathrm{h}$ in energy of type $\mathrm{k}$. Based on the input-output model for one product family, the environmental impacts depend on the types of waste $\left(\mathrm{w}_{\mathrm{k}}\right)$, types of primary inputs $\left(\mathrm{r}_{\mathrm{k}}\right)$, and types of energy $\left(\mathrm{e}_{\mathrm{k}}{ }_{\mathrm{k}}-\mathrm{e}_{\mathrm{k}}^{s}\right)$. The environmental impact of the ID for the actual set of final demand of product $\mathrm{i}, \mathrm{f}_{\mathrm{i}}$, is given by the set of values $\left(\mathrm{f}_{\mathrm{i}}, \mathrm{r}_{\mathrm{k}}, \mathrm{e}_{\mathrm{k}}^{d}, \mathrm{w}_{\mathrm{k}}\right)$ for all $\mathrm{i}$ and $\mathrm{k}$ relevant for the analysis, if no waste-energy transformation is performed. Graphically, the environmental impact can be represented as in Figure 2 (continuous line).

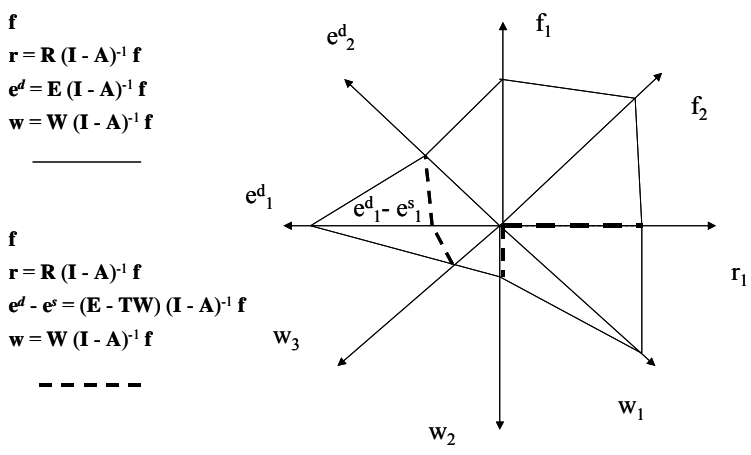

Figure 2. Environmental impact of an industrial district for two main products, one primary input, three types of waste and two types of energy with no waste-energy transformation (continuous line) and with waste-energy transformation (dotted line) related to $\mathrm{w}_{1}$ and $\mathrm{e}^{\mathrm{s}}$.

If waste-energy transformation is performed, the environmental impact of the ID for the actual set of final demand of product $i, f_{i}$, is given by the set of values $\left(f_{i}, r_{k}\right.$, 
$\mathrm{e}_{\mathrm{k}}^{d}-\mathrm{e}_{\mathrm{k}}^{s}, \mathrm{w}_{\mathrm{k}}$ ) for all $\mathrm{i}$ and $\mathrm{k}$ relevant for the analysis and it is depicted in Figure 2 (dotted line). Comparing the above impacts it is possible to observe the change caused by the reduction of energy consumption and the change of wastes caused by the related transformation. The environmental impact for unitary demand of a given product $i\left(f_{i}=1\right)$ can be obtained by the set of values $\left(\mathrm{f}_{\mathrm{i}}=1, \mathrm{f}_{\mathrm{j}}=0, \mathrm{r}_{\mathrm{k}}, \mathrm{e}^{d}{ }_{\mathrm{k}}-\mathrm{e}_{\mathrm{k}}^{s}\right.$, $\mathrm{w}_{\mathrm{k}}$ ) for all $\mathrm{j} \neq \mathrm{i}$ and for all $\mathrm{k}$ relevant for the analysis and it is represented in Figure 3. Another kind of environmental impact can be referred for each waste of type $\mathrm{k}$ as the amount $w_{k}^{i}$ of $w_{k}$ produced for each $f_{i}$; graphically it is depicted in Figure 4. Similar impacts can be defined referring to each primary input and type of energy.

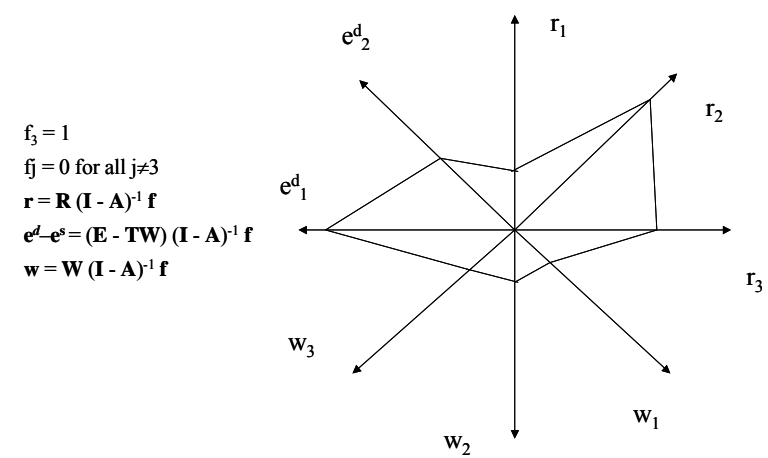

Figure 3. Environmental impact of an industrial district for the unitary demand of product 3 , for three primary inputs, two types of waste, and two types of energy.

$$
\begin{aligned}
& \mathrm{w}_{3}{ }^{1}=\mathrm{D}_{31} \mathrm{f}_{1} \\
& \mathrm{w}_{3}{ }^{2}=\mathrm{D}_{32} \mathrm{f}_{2} \\
& \mathrm{w}_{3}{ }^{3}=\mathrm{D}_{33} \mathrm{f}_{3} \\
& \mathrm{w}_{3}{ }^{4}=\mathrm{D}_{34} \mathrm{f}_{4} \\
& \mathrm{w}_{3}{ }^{5}=\mathrm{D}_{35} \mathrm{f}_{5} \\
& \text { with } \mathbf{D}=\mathbf{W}(\mathbf{I}-\mathbf{A})^{-1}
\end{aligned}
$$

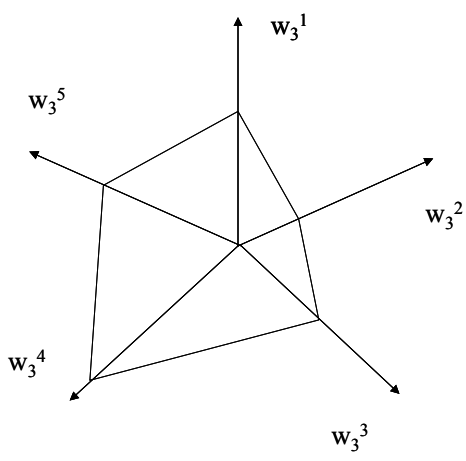

Figure 4. Environmental impact of an industrial district for $\mathrm{w}_{3}$ and for five main products.

It is important to underline that the environmental impact evaluated per unit of product can be related to the efficiency of the production cycle in the district, whereas those evaluated with total values represent the impact of the district on the local area.

With the present model it is possible to take into account more than one DPPN. Initially, let us assume two DPPNs corresponding to the $\mathrm{p}$-th and the q-th product families (consider the definition of family given at page 12). If the union of the two sets of processes is considered (outputs of product $\mathrm{j}$ or of energy of type $\mathrm{k}$ for the $\mathrm{p}$-th and q-th product families), the resulting model is:

$$
\begin{aligned}
& x^{p, q}=\left(I-A^{p, q}\right)^{-1} f^{p, q} \\
& r^{p, q}=R^{p, q} x^{p, q} \\
& e^{p, q d}=E^{p, q} x^{p, q} \\
& w^{p, q}=W^{p, q} x^{p, q} \\
& e^{p, q s}=T^{p, q} w^{p, q}
\end{aligned}
$$

Technical coefficients are estimated using the same approach as in the case of one product family. Environmental impacts for all DPPNs identified within a district can then be easily computed.

\section{Case Study Examples}

In this section, the environmental impacts for two industrial districts located in Italy, namely Sassuolo and Matera, are evaluated. Based on data gathered from the field, the input-output balance tables are built and used as accounting tools to compute materials, energy, and waste flows thus providing a measure of resources consumption and environmental impact of the district. The environmental impacts are then built for primary inputs, energy and waste products per unit of final product and for the total amounts of products produced.

The first case example presented in this section refers to the Italian industrial district of Sassuolo where tiles are manufactured. The main production processes that compose one of the district production process networks, that of the mono-cooking tiles (Figure 5), are:

Mixing process: the clay, crude wastes reused and other materials (that depend on the type of tiles to be produced) are grounded, sifted and mixed with water and mud;

Pressing and drying process: the mixed clay is first pressed and then dried to obtain crude dried tiles that are then decorated in the glazing process;

Cooking process: it is a continuous process that has the scope to consolidate the tiles and fix the glazing; it is composed of preheating, cooking and cooling;

Selection and packaging process: tiles are selected according to quality and color and are then packaged by machines that automatically put the tiles in boxes.

In terms of outputs, each process is characterized by a single main product (a specific intermediate or end product), and by waste, pollution and by-products. Based on the district production process network indicated in Figure 5, a material/energy balance table on a yearly basis can be established (Table 1); it represents the actual material/energy accounting for this series of end product. The present data (in physical units) are distributed in five sections: intermediate consumption of main products, imports, primary inputs, energy inputs, and by-product and waste outputs. The last line is the recall of the gross outputs of the main product of each process. Imports are considered in this case to indicate the fraction of intermediate products bought from a process that does not belong to the district. 
Table 1. Balance Table for the DPPN of Mono-cooking Tiles in the ID of Sassuolo

\begin{tabular}{|c|c|c|c|c|c|c|c|}
\hline & & \multicolumn{5}{|c|}{ Production processes } & \multirow[b]{3}{*}{$\begin{array}{c}\text { Final } \\
\text { demand }\end{array}$} \\
\hline & & $\mathrm{A}$ & $\mathrm{B}$ & $\mathrm{C}$ & $\mathrm{D}$ & $\mathrm{E}$ & \\
\hline $\begin{array}{l}\text { Production processes and } \\
\text { main products }\end{array}$ & Units per year $\left(\times 10^{5}\right)$ & \multicolumn{5}{|c|}{ Intermediate consumption of main products } & \\
\hline A - Clay mixture & $\mathrm{t}$ & 0 & 27.95 & 0 & 0 & 0 & 0 \\
\hline B - Dried tiles & $\mathrm{t}$ & 0 & 0 & 28 & 0 & 0 & 0 \\
\hline C - Glazed tiles & $\mathrm{t}$ & 0 & 0 & 0 & 27.20 & 0 & 0 \\
\hline D - Cooked tiles & $\mathrm{t}$ & 0 & 0 & 0 & 0 & 27.23 & 0 \\
\hline E - Packaged tiles & $\mathrm{t}$ & 0 & 0 & 0 & 0 & 0 & 26.70 \\
\hline Types of imports & Units per year $\left(\times 10^{5}\right)$ & \multicolumn{5}{|c|}{ Imports } & Total \\
\hline A' - Clay mixture & $\mathrm{t}$ & 0 & 0.48 & 0 & 0 & 0 & 0.484 \\
\hline Types of purchased inputs & Units per year $\left(\times 10^{5}\right)$ & \multicolumn{5}{|c|}{ Primary inputs } & Total \\
\hline 1 - Crude wastes reused $*$ & $\mathrm{t}$ & 0.086 & 0 & 0 & 0 & 0 & 0.086 \\
\hline 2 - Clay & $\mathrm{t}$ & 28.17 & 0 & 0 & 0 & 0 & 28.17 \\
\hline 3 - Washing mud reused $*$ & $\mathrm{t}$ & 0.35 & 0 & 0 & 0 & 0 & 0.35 \\
\hline 4 - Glaze & $\mathrm{t}$ & 0 & 0 & 0.16 & 0 & 0 & 0.16 \\
\hline 5 - Water & $\mathrm{m}^{3}$ & 16.91 & 0.46 & 2. 61 & 0 & 0 & 19.98 \\
\hline 6 - Recycled water $*$ & $\mathrm{~m}^{3}$ & 0 & 0 & 0.39 & 0 & 0 & 0.39 \\
\hline Types of energy inputs & Units per year $\left(\times 10^{5}\right)$ & \multicolumn{5}{|c|}{ Energy inputs } & Total \\
\hline Electric power & $\mathrm{MWh}$ & 1.53 & 1.15 & 0.16 & 0.75 & 0.14 & 3.73 \\
\hline $\begin{array}{l}\text { Thermal power (natural } \\
\text { gas) }\end{array}$ & Kcal & $70 \times 10^{5}$ & $30.8 \times 10^{5}$ & 0 & $190 \times 10^{5}$ & $20 \times 10^{5}$ & $310.8 \times 10^{5}$ \\
\hline $\begin{array}{l}\text { Types of by-products \& } \\
\text { waste outputs }\end{array}$ & Units per year $\left(\times 10^{5}\right)$ & \multicolumn{5}{|c|}{ Output of by-products and waste } & Total \\
\hline 1 - Crude wastes * & $\mathrm{t}$ & 0 & 0.436 & 0 & 0 & 0 & 0.436 \\
\hline 2 -Washing mud * & $\mathrm{t}$ & 0.401 & 0 & 0 & 0 & 0 & 0.401 \\
\hline 3 - Mud & $\mathrm{t}$ & 0 & 0 & 0.303 & 0 & 0 & 0.303 \\
\hline 4 - Cooked wastes & $\mathrm{t}$ & 0 & 0 & 0 & 0.627 & 0.604 & 1.231 \\
\hline 5 - Glazed crude wastes & $\mathrm{t}$ & 0 & 0 & 0.675 & 0 & 0 & 0.675 \\
\hline 6 - Flowing water* & $\mathrm{m}^{3}$ & 2.913 & 0 & 2.278 & 0 & 0 & 5.191 \\
\hline $7-\mathrm{CO}_{2}$ & $\mathrm{Kg}$ & 1580 & 695.8 & 0 & 4291.8 & 451.8 & 7019.4 \\
\hline \multicolumn{2}{|c|}{ Gross output of main products $x_{\mathrm{j}}\left(\times 10^{5}\right)$} & 27.95 & 28 & 27.20 & 27.23 & 26.70 & \\
\hline
\end{tabular}

indicates flows of reused materials

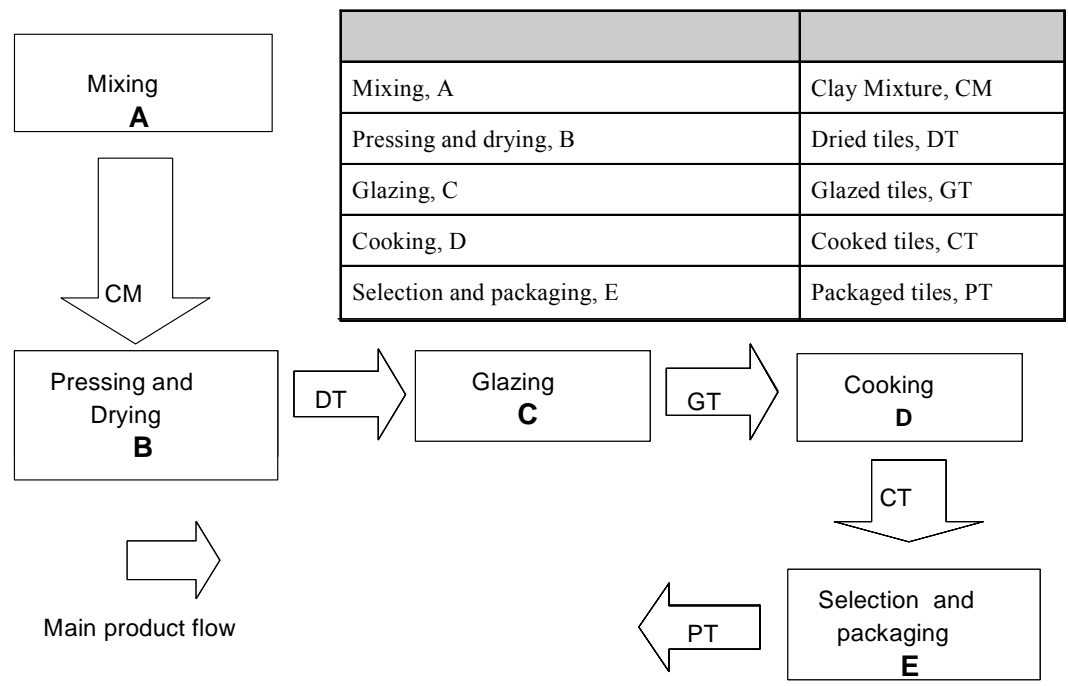

Figure 5. District production process network of mono-cooking tiles in the Sassuolo ID. 
It can be noted that some inputs are recycled waste; these products (e.g., water) are indicated in the table with a star. The district operator is rather careful in terms of rational use of the resources and has recently developed a system to monitor water flows and energy consumption. For the given product family in the district there is only one end product, packaged tiles. Then the environmental impacts can be drawn as described in the previous section. In particular, referring to the nomenclature and data in Table 1, for the final demand $f_{\mathrm{E}}$ two environmental impacts can be drawn. In Figure 6 the environmental impact is given by values per unit of end product. One can notice that for example in the district of Sassuolo to produce one ton of tiles the use of water amounts to 0.75 $\mathrm{m}^{3}$, the electric power required is $0.14 \mathrm{MWh}$, and 262.90 $\mathrm{kg}$ of $\mathrm{CO}_{2}$ are produced. These measures can be very useful when comparing districts that produce the same kind of end products as it gives immediately the amount of resources used and wastes produced per unit of product and can help understand which one is more efficient. In particular, this gives the specific consumes of materials and energy and allows them to proceed with the evaluation of the efficiency of a district as time goes on.

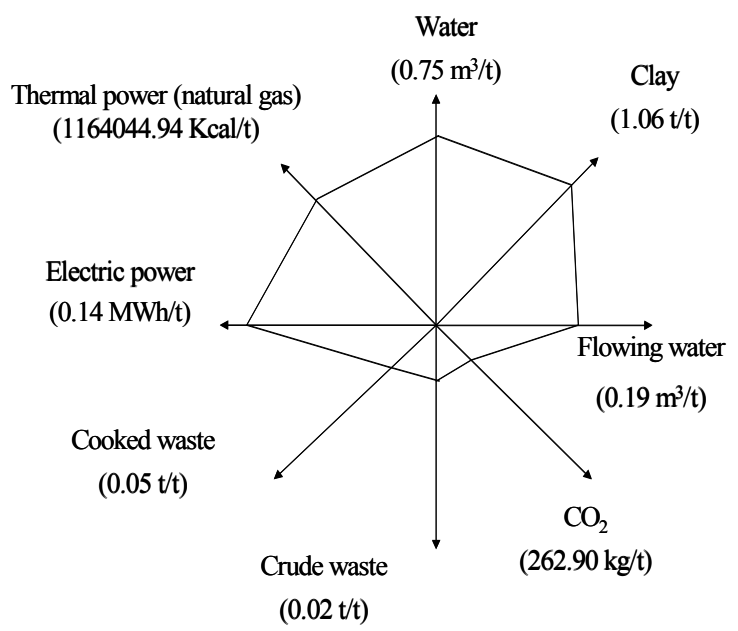

Figure 6. Sassuolo ID environmental impact per unit of end product for two primary inputs, four types of waste and two types of energy $\left(\mathrm{r}_{2}, \mathrm{r}_{5}, \mathrm{w}_{1}, \mathrm{w}_{4}, \mathrm{w}_{6}, \mathrm{w}_{7}, \mathrm{e}_{\text {el }}^{\mathrm{d}}, \mathrm{e}_{\text {th }}^{\mathrm{d}}\right)$.

In Figure 7 the environmental impact is given simply by the set of values considered relevant taken from the input-output balance table $\left(\mathrm{r}_{2}, \mathrm{r}_{5}, \mathrm{w}_{1}, \mathrm{w}_{4}, \mathrm{w}_{6}, \mathrm{w}_{7}, \mathrm{e}_{\mathrm{el}}^{\mathrm{d}}, \mathrm{e}^{\mathrm{d}}{ }_{\text {th }}\right)$. It gives the impact on the territory. In fact one can see that to produce $2.6710^{6}$ tons of tiles the total amount of water required in a year is $1.99810^{6} \mathrm{~m}^{3}, 3.72610^{5} \mathrm{MWh}$ of electric power are required and in terms of $\mathrm{CO}_{2} 7.01910^{8}$ are produced. This impact can be important when comparing any districts as it shows the impact that it has on the environment, i.e. in terms of water or electric energy required. This is what is done in the present section comparing the two districts examined.

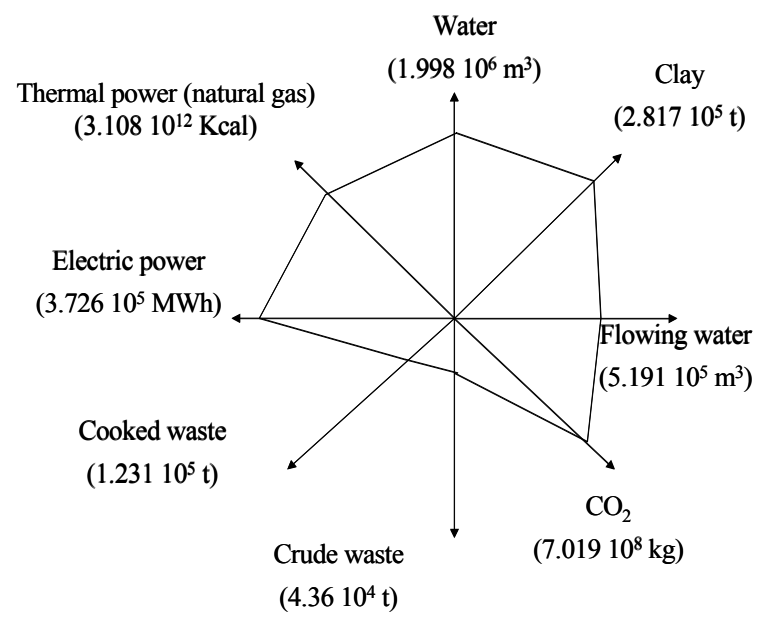

Figure 7. Sassuolo ID environmental impact for the amount of end product $f_{E}\left(2.6710^{6} t\right)$, two primary inputs, four types of waste and two types of energy $\left(\mathrm{f}_{\mathrm{E}}, \mathrm{r}_{2}, \mathrm{r}_{5}, \mathrm{w}_{1}\right.$, $\left.\mathrm{w}_{4}, \mathrm{w}_{6}, \mathrm{w}_{7}, \mathrm{e}_{\mathrm{el}}^{\mathrm{d}}, \mathrm{e}_{\text {th }}^{\mathrm{d}}\right)$.

The second case example presented in this section refers to the Italian industrial district of Matera, where leather upholstery is manufactured. The main production processes that compose one of the district production process network, that of the leather sofas (Figure 8), are:

Frame realization: the wood is processed to produce the frame of the sofa;

Strapping: appropriate elastic straps are fixed on the frame to give flexibility to the sofa;

Frame preparation: polyurethane of type $\mathrm{p}$ is glued to the strapped frame;

Polyurethane cutting: polyurethane of type e is shaped;

Leather cutting: in the first place leather imperfections are detected, then the molds are positioned and the leather is cut;

Leather stitching: the cut leather is sewed together according to design schemes;

Assembling: all the pieces are assembled manually;

Controlling: the final product is controlled and a label applied if the sofa is acceptable.

As in the previous case example, based on the district production process network indicated in Figure 8, a material/energy balance table referring to one year can be completed (Table 2).

Referring to nomenclature and data in Table 2, for the final demand $\mathrm{f}_{8}$, i.e., controlled seats, three environmental impacts can be drawn. In Figure 9 the impact is given by values per unit of end product considering the set $\left(\mathrm{r}_{2}, \mathrm{r}_{6}\right.$, $\left.\mathrm{r}_{9}, \mathrm{w}_{4}, \mathrm{w}_{9}, \mathrm{w}_{10}, \mathrm{e}^{\mathrm{d}}{ }_{\mathrm{el}}, \mathrm{e}^{\mathrm{d}}{ }_{\mathrm{th}}\right)$. So for example $4.73 \mathrm{~m}^{2}$ of leather and $0.04 \mathrm{MWh}$ of electric power are required and $1.89 \mathrm{~m}^{2}$ of leather waste are produced per unit of seat produced. 
Table 2. Balance Table for the DPPN of Leather Sofas in the ID of Matera

\begin{tabular}{|c|c|c|c|c|c|c|c|c|c|c|}
\hline & & \multicolumn{8}{|c|}{ Production processes } & \\
\hline & & 1 & 2 & 3 & 4 & 5 & 6 & 7 & 8 & \\
\hline $\begin{array}{l}\text { Production } \\
\text { processes }\end{array}$ & $\begin{array}{l}\text { Units per year } \\
\qquad\left(\times 10^{5}\right)\end{array}$ & \multicolumn{8}{|c|}{ Intermediate consumption of main products } & $\begin{array}{l}\text { Final } \\
\text { demand }\end{array}$ \\
\hline 1 & n. of FS & 0 & 180 & 0 & 0 & 0 & 0 & 0 & 0 & 0 \\
\hline 2 & n. of SFS & 0 & 0 & 180 & 0 & 0 & 0 & 0 & 0 & 0 \\
\hline 3 & n. of PFS & 0 & 0 & 0 & 0 & 0 & 0 & 180 & 0 & 0 \\
\hline 4 & $\mathrm{~m}^{3}$ of $\mathrm{CP}$ & 0 & 0 & 0 & 0 & 0 & 0 & 382 & 0 & 0 \\
\hline 5 & $\mathrm{~m}^{2}$ of $\mathrm{CL}$ & 0 & 0 & 0 & 0 & 0 & 511 & 0 & 0 & 0 \\
\hline 6 & $\mathrm{~m}^{2}$ of $\mathrm{LC}$ & 0 & 0 & 0 & 0 & 0 & 0 & 511 & 0 & 0 \\
\hline 7 & n. of AS & 0 & 0 & 0 & 0 & 0 & 0 & 0 & 180 & 0 \\
\hline 8 & n. of CS & 0 & 0 & 0 & 0 & 0 & 0 & 0 & 0 & 180 \\
\hline $\begin{array}{l}\text { Types of primary } \\
\text { inputs }\end{array}$ & $\begin{array}{l}\text { Units per year } \\
\qquad\left(\times 10^{5}\right)\end{array}$ & \multicolumn{8}{|c|}{ Primary inputs } & Total \\
\hline 1 - Shaving & $\mathrm{m}^{3}$ & 164 & 0 & 0 & 0 & 0 & 0 & 0 & 0 & 164 \\
\hline 2 - Wood-layer & $\mathrm{m}^{3}$ & 30.3 & 0 & 0 & 0 & 0 & 0 & 0 & 0 & 30.3 \\
\hline 3 - Masonite & $\mathrm{m}^{3}$ & 105 & 0 & 0 & 0 & 0 & 0 & 0 & 0 & 105 \\
\hline 4 - Fir-wood & $\mathrm{m}^{3}$ & 14.5 & 0 & 0 & 0 & 0 & 0 & 0 & 0 & 14.5 \\
\hline 5 - Polyurethane $p$ & $\mathrm{~m}^{3}$ & 0 & 0 & 89 & 0 & 0 & 0 & 0 & 0 & 89 \\
\hline 6 - Polyurethane e & $\mathrm{m}^{3}$ & 0 & 0 & 0 & 419.4 & 0 & 0 & 0 & 0 & 419.4 \\
\hline 7 - Resinato & $\mathrm{m}^{3}$ & 0 & 0 & 66.2 & 0 & 0 & 0 & 0 & 0 & 66.2 \\
\hline 8 - Wadding & $\mathrm{m}^{3}$ & 0 & 0 & 0 & 0 & 0 & 0 & 87.8 & 0 & 87.8 \\
\hline 9 - Leather & $\mathrm{m}^{2}$ & 0 & 0 & 0 & 0 & 851.5 & 0 & 0 & 0 & 851.5 \\
\hline 10 - Nets & Number & 0 & 0 & 0 & 0 & 0 & 0 & 90 & 0 & 90 \\
\hline 11 - Feet & Number & 0 & 0 & 0 & 0 & 0 & 0 & 540 & 0 & 540 \\
\hline 12 - Strap & $\mathrm{m}$ & 0 & 691 & 0 & 0 & 0 & 0 & 0 & 0 & 691 \\
\hline 13 - Nylon & $\mathrm{m}$ & 0 & 0 & 0 & 0 & 0 & 14256 & 0 & 0 & 14256 \\
\hline $\begin{array}{l}\text { Types of energy } \\
\text { inputs }\end{array}$ & $\begin{array}{l}\text { Units per year } \\
\qquad\left(\times 10^{5}\right)\end{array}$ & \multicolumn{8}{|c|}{ Energy inputs } & Total \\
\hline Electric power & MWh & 1.73 & 0.86 & 2.07 & 0.95 & 0.43 & 0.72 & 0.81 & 0.36 & 7.93 \\
\hline Low energy heat & Kcal & 0 & 0 & 0 & 126720 & 0 & 0 & 220320 & 0 & 347040 \\
\hline \multicolumn{11}{|c|}{ Output of by-products and waste } \\
\hline 1- Shaving & $\mathrm{m}^{3}$ & 0.69 & 0 & 0 & 0 & 0 & 0 & 0 & 0 & 0.69 \\
\hline 2- Wood-layer & $\mathrm{m}^{3}$ & 0.22 & 0 & 0 & 0 & 0 & 0 & 0 & 0 & 0.22 \\
\hline 3- Masonite & $\mathrm{m}^{3}$ & 0.11 & 0 & 0 & 0 & 0 & 0 & 0 & 0 & 0.11 \\
\hline 4- Fir-wood & $\mathrm{m}^{3}$ & 0.42 & 0 & 0 & 0 & 0 & 0 & 0 & 0 & 0.42 \\
\hline 5- Polyurethane $p$ & $\mathrm{~m}^{3}$ & 0 & 0 & 8.10 & 0 & 0 & 0 & 0 & 0 & 8.10 \\
\hline 6- Polyurethane $e$ & $\mathrm{~m}^{3}$ & 0 & 0 & 0 & 37.7 & 0 & 0 & 0 & 0 & 37.7 \\
\hline 7- Resinato & $\mathrm{m}^{3}$ & 0 & 0 & 5.96 & 0 & 0 & 0 & 0 & 0 & 5.96 \\
\hline 8- Wadding & $\mathrm{m}^{3}$ & 0 & 0 & 0 & 0 & 0 & 0 & 7.90 & 0 & 7.90 \\
\hline 9- Leather & $\mathrm{m}^{2}$ & 0 & 0 & 0 & 0 & 340.62 & 0 & 0 & 0 & 340.62 \\
\hline $10-\mathrm{CO}_{2}$ & $\mathrm{Kg}$ & 0 & 0 & 0 & 25.92 & 0 & 0 & 70.90 & 0 & 96.82 \\
\hline $11-\mathrm{SOx}$ & $\mathrm{Kg}$ & 0 & 0 & 0 & 0 & 0 & 0 & 0.14 & 0 & 0.14 \\
\hline 12- NOx & $\mathrm{Kg}$ & 0 & 0 & 0 & 0.036 & 0 & 0 & 0.077 & 0 & 0.113 \\
\hline 13-PST & $\mathrm{Kg}$ & 0 & 0 & 0 & 0.0012 & 0 & 0 & 0.0032 & 0 & 0.0044 \\
\hline $\begin{array}{l}\text { Gross output of main } \\
\text { products } x_{\mathrm{j}}\left(\times 10^{5}\right)\end{array}$ & & 180 & 180 & 180 & 382 & 511 & 511 & 180 & 180 & \\
\hline
\end{tabular}




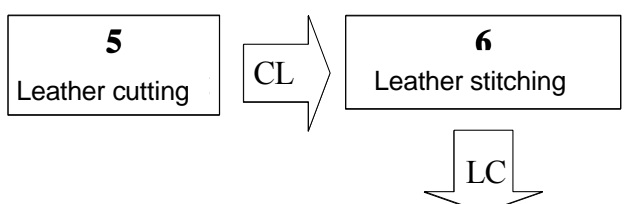

\begin{tabular}{|l|l|}
\hline Production processes & Main products \\
\hline 1: Frame realization & Framed seats, FS \\
\hline 2: Strapping & Strapped frame seats, SFS \\
\hline 3: Frame preparation & Prepared frame seats, PFS \\
\hline 4: Polyurethane cutting & Cut polyurethane, CP \\
\hline 5: Leather cutting & Cut Leather, CL \\
\hline 6: Leather stitching & Leather covering, LC \\
\hline 7: Assembling & Assembled seats, AS \\
\hline 8: Controlling & Controlled seats, CS \\
\hline
\end{tabular}

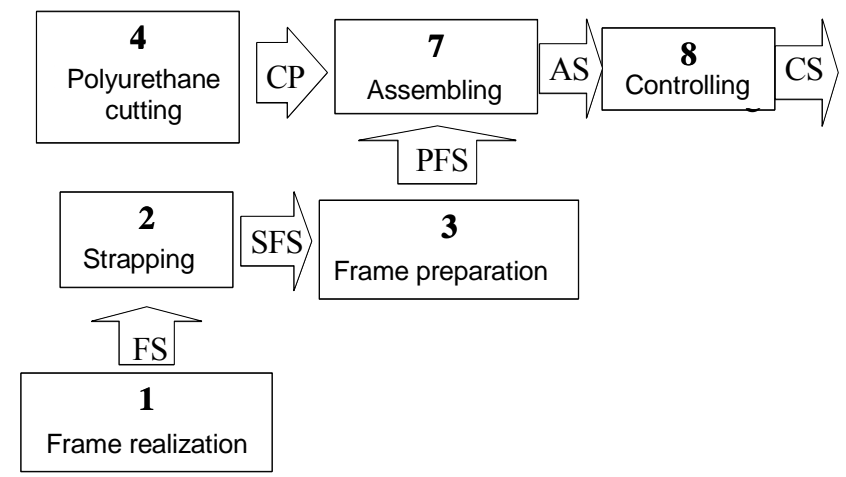

Figure 8. District production process network of the leather sofas in the industrial district located in Matera.

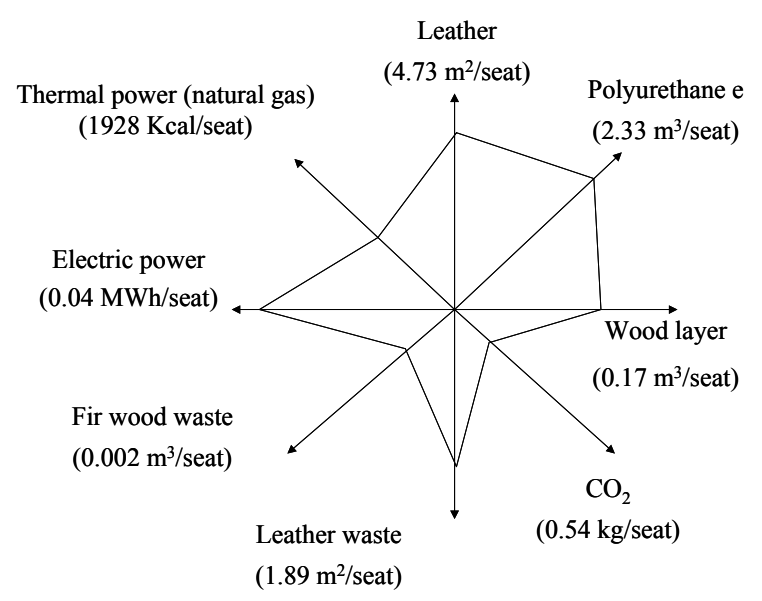

Figure 9. Matera ID environmental impact per unit of end product for three primary inputs, three types of waste and two types of energy $\left(r_{2}, r_{6}, r_{9}, w_{4}, w_{9}, w_{10}, e^{d}{ }_{e l}, e^{d}{ }_{t h}\right)$.

In Figure 10 the environmental impact is given simply by the set of values considered relevant taken from the input-output balance table $\left(\mathrm{f}_{8}, \mathrm{r}_{2}, \mathrm{r}_{6}, \mathrm{r}_{9}, \mathrm{~W}_{4}, \mathrm{w}_{9}, \mathrm{~W}_{10}, \mathrm{e}_{\mathrm{el}}^{\mathrm{d}}\right.$, $\mathrm{e}_{\mathrm{th}}^{\mathrm{d}}$ ). So for example $8.51510^{7} \mathrm{~m}^{2}$ of leather are required in total in a year and $3.40610^{7}$ is the total leather waste produced.

The comparison between this figure and Figure 7, related to the Sassuolo district, shows that the district of Sassuolo needs more energy, both electric and thermal, and also it needs a large amount of water. The environmental problems related to the district of Matera are instead related to the use of leather and the production of wood and leather wastes.

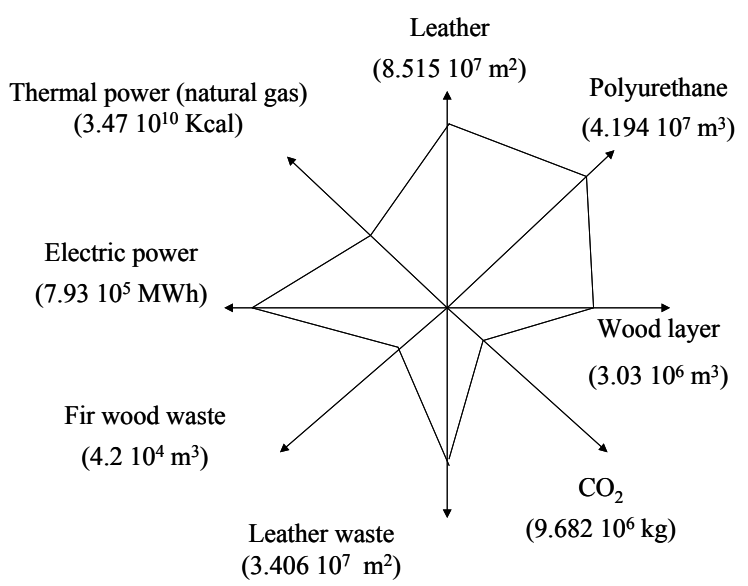

Figure 10. Matera ID environmental impact for the amount of end product $\mathrm{f}_{8}\left(1.810^{7}\right.$ seats), for three primary inputs, three types of waste and two types of energy $\left(r_{2}, r_{6}\right.$, $\left.\mathrm{r}_{9}, \mathrm{w}_{4}, \mathrm{w}_{9}, \mathrm{w}_{10}, \mathrm{e}_{\mathrm{el}}^{\mathrm{d}}, \mathrm{e}_{\mathrm{th}}^{\mathrm{d}}\right)$.

In Figure 11 two impacts are presented: the continuous line gives the set of values drawn from the input-output balance table, $\left(\mathrm{f}_{8}, \mathrm{w}_{1}, \mathrm{w}_{2}, \mathrm{w}_{3}, \mathrm{w}_{4}, \mathrm{w}_{10}, \mathrm{e}_{\mathrm{el}}^{\mathrm{d}}\right.$, $\left.\mathrm{e}^{\mathrm{d}} \mathrm{th}_{\mathrm{t}}\right)$, where all the wooden wastes are accounted for, whereas the dotted line presents the impact with waste-energy transformation of all the wooden scraps. For the waste transformation a biomass plant is considered that produces both electric and thermal energy. It is easy to understand that in this case the environmental footprint of the district is much reduced even if the $\mathrm{CO}_{2}$ emissions increase (this very much depends on the type of plant and filters used). However, an amount of $1.3310^{11} \mathrm{Kcal}$ exceeds the district consumption and could be used for local community needs. 


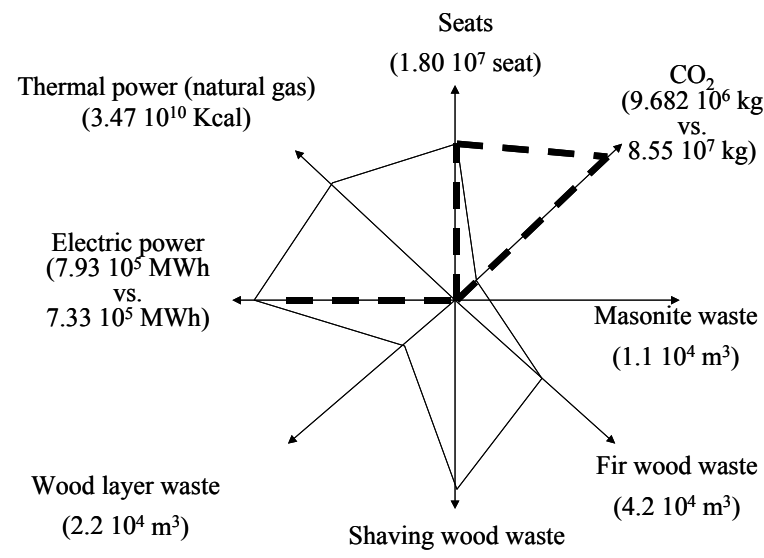

$\left(6.910^{4} \mathrm{~m}^{3}\right)$

Figure 11. Environmental impact $\left(\mathrm{f}_{8}, \mathrm{w}_{1}, \mathrm{w}_{2}, \mathrm{w}_{3}, \mathrm{w}_{4}, \mathrm{w}_{10}\right.$ $\mathrm{e}_{\mathrm{el}}^{\mathrm{d}}, \mathrm{e}_{\mathrm{th}}^{\mathrm{d}}$ ) (continuous line) versus environmental impact with waste-energy transformation of all the wood scraps $\left(\mathrm{f}_{8}, \mathrm{w}_{1}, \mathrm{w}_{2}, \mathrm{w}_{3}, \mathrm{w}_{4}, \mathrm{w}_{10}, \mathrm{e}_{\mathrm{el}}^{\mathrm{d}}-\mathrm{e}_{\mathrm{el}}^{\mathrm{s}}, \mathrm{e}_{\text {th }}^{\mathrm{d}}-\mathrm{e}_{\text {th }}^{\mathrm{s}}\right)$ (dotted line), referred to Matera ID.

\section{Conclusions}

The relevance of industrial districts where competitive models are able to sustain the development of a local area, providing firms with positive externalities has been discussed. However, the agglomeration of production activities in a limited area determines environmental problems that need to be carefully evaluated. In view of developing countries, new industrial policies, which encourage the use of renewable energy sources and constrain water usage, are essential in the context of sustainability. In the paper, the concept of environmental impact through the use of an input-output model enables us to take into account the complex network of materials and energy flows within the district. This assessment is able to show the impact of production processes providing private and public managers as well as the local community with quantitative measures. The total and the specific impacts (i.e., per unit of product output) are quantified in terms of resources used, wastes produced and energy consumed. Also, specific insights can be drawn on the technology adopted and on the local re-use and recycle policy. Industrial districts are adopted in developing countries as models of industrial development. Therefore, in the discussion of sustainable development it becomes mandatory to quantify and monitor the real impact of any process on the environment. In particular, it is important to consider both aggregated and specific impacts, especially when it comes to policies to reduce pollution production and energy and water resources use.

Two case study examples, the Italian industrial districts of Sassuolo and Matera, have been analyzed. The environmental impacts obtained by the input-output accounting model applied to the districts point out the

most relevant types of primary inputs and of energy used, and types of waste produced. The quantitative measure of benefits obtainable, for instance, by using wood wastes to produce electric and thermal energy in the ID of Matera is compared with the consequent increase of $\mathrm{CO}_{2}$. The assessment of environmental impacts carried out in this way seems also particularly suitable to show, in a simple and effective way, which product or process within the district is responsible for the highest impact on the local environment. The critical issue remains the data gathering, even if IDs are characterized by high homogeneity in terms of organization and technology adopted for processes related to the same phase. The research will be extended to IDs that are more critical in terms of impact on their local environment. This can be useful to provide companies and public administrations with recommendations based on integrated and systemic information.

\section{References}

Albino, V., Izzo, C. and Kühtz, S. (2000). Input-output process model for materials/energy flow analysis of an industrial district, in the XIII International Conference on Input-Output Techniques, Macerata, Italy, August 21-25 $5^{\text {th }}, 2000$.

Albino, V., Izzo, C. and Kühtz, S. (2002). Input-output models for the analysis of a local/global supply chain. Int. J. Product. Econ., 78, 119-131.

Albino, V., Dietzenbacher, E. and Kühtz, S. (2003). Materials/energy flow analysis of an industrial district using an input-output model. Econ. Systems Res., 15(4) (forthcoming).

Ambiente Italia (2000). Distretti industriali e innovazione ambientale, Legambiente Documenti, Emilia-Romagna, Bologna, Italy.

Ambiente Italia (2001). Ecodistretti 2001. Politiche ambientali innovative nei distretti industriali italiani, Legambiente Documenti, http://www.legambientedoc.it/centro/documenti/2001/ecodi-str etti2001.htm.

Aydalot, P. (1988). Technological trajectories and regional innovation in Europe, in P. Aydalot and D. Keeble (Eds.), High Technology Industry and Innovative Environments: The European Experience, Routledge, London, UK.

Bagnasco, A. (1988). La costruzione sociale del mercato, Il Mulino, Bologna, Italy.

Barry, J., Girard, G. and Perras, C. (1993). Logistic planning shifts into reverse. J. Eur. Bus., September/October, 34-38

Beamon, B.M. (1999a). Designing the green supply chain. Logist. Info. Manage., 12(4), 332-342.

Beamon, B.M. (1999b). Measuring supply chain performance. Int. J. Oper. Prod. Manage., 19(3), 275-292.

Becattini, G. (1989). Riflessioni sul distretto industriale marshalliano come concetto socio-economico. Stato e Mercato, 25, 111-128.

Becattini, G., Pyke, F., and Sengenberger, W. (Eds.) (1992). Industrial districts and Inter-firm co-operation in Italy, International Institute for Labour Studies, Geneva.

Bloemhof-Ruwaard, J.M., van Beek, P., Hordijk, L., Van Wassenhove, L.N. (1995). Interactions between operational research and environmental management. Eur. J. Oper. Res., 85, 229-243.

Borghini, S. and Cibin, M. (1999). Lo stato dell'arte della gestione ambientale d'impresa nel triveneto rispetto al territorio nazionale ed Europeo: Presentazione dell'analisi empirica della FEEM su 200 imprese del Triveneto, in Proc. of the 
Conference "Gestione Ambientale d'impresa nel Triveneto: le azioni, le spinte, gli ostacoli ed i percorsi per il futuro", Fondazione Eni Enrico Mattei, Venezia, Italy, March $26^{\text {th }}$, 1999.

de Bruijn, T.J.N.M. and Hofman, P.S. (2000). Pollution prevention in small and medium-sized enterprises, GMI 30 Greenleaf Publishing, summer, http://www. greenleaf -publishing.com/pdfs/debruijn.pdf.

Hamner, B. and Del Rosario, T. (1997). Green purchasing: a global channel for improving the environmental performance of small enterprises, in Proc. of the Workshop on "Globalisation and the environment: new challenges for the public and private sectors", Paris, France, November 13-14 $4^{\text {th }}, 1997$.

Holliday, C. (2001). Sustainable growth, the Dupont way. Harvard Bus. Rev., 79(8), 129-134.

Isard, W. and Schooler, E.W. (1959). Industrial complex cnalysis, agglomeration economies and regional development. J. Reg. Sci., 1, 19-23.

Isard, W., Schooler, F.W. and Vietorisz, T. (1959). Industrial Complex Analysis and Regional Development, MIT Press, MA, USA.

Isard, W. and Vietorisz, T. (1955). Industrial complex analysis and regional development, in Proc. of the Regional Science Association, Vol. 1.

Jasch, C. (2000). Environmental performance evaluation and indicators. J. Clean. Prod., 8, 79-88.

Loinger, G. and Peyrache, V. (1988). Technological clusters and regional restructuring, in P. Aydalot and D. Keeble (Eds.), High Technology Industry and Innovative Environments: The European Experience, Routledge, London, UK.

Markusen, A. (1996). Sticky places in slippery space: A typology of industrial districts. Econ. Geogr., 72(3), 293-313.

Marshall, A. (1920). Industry and Trade, Macmillan, London, UK.

Nathani, C. (2000). Linking an IO model with a material flow model to assess structural change related to material efficiency strategies. An application to the Paper Cycle, in the XIII International Conference on Input-Output Techniques, Macerata, Italy, August $21-25^{\text {th }}, 2000$.

OECD (2000). Local partnership, clusters and SME globalisation, in the Report of the Conference for Ministers Responsible for SMEs and Industry Ministers, Bologna, Italy, June 14-15 ${ }^{\text {th }}$,
2000.

Piore, M. and Sabel, C. (1984). The Second Industrial Divide: Possibilities for Prosperity, Basic Books, New York, NY, USA.

Polenske, K.R. (1997). Linked system of enterprise, regional and national Input-output accounts for policy analysis, in M. Chatterji (Ed.), Regional Science: Perspectives for the Future, MacMillan, London, UK.

Polenske, K.R. (2001). Competitive advantage of regional internal and external supply chain, in M.L. Lahr and R. Miller (Eds), Perspectives in Regional Science: A Festschrift in Memory of Benjamin Stevens, Elsevier, Amsterdam, Netherlands, pp. 259-300.

Porter, M.E. (1998). Clusters and the new economics of competition. Harvard Bus. Rev., 76(6), 77-90.

Rabellotti, R. (1995). Is there an "Industrial District Model"? Footwear districts in Italy and Mexico compared. World Devel., 23(1), 29-41.

Renn, O., Goble, R. and Kastenholz, H. (1998). How to apply the concept of sustainability to a region. Technol. Forecast. Soc. Change, 58, 63-81.

Saxenian, A. (1999). Regional Advantage. Culture and Competition in Silicon Valley and Route 128, Harvard University Press, Cambridge, MA, USA.

Schendler, A. (2002). Where's the green in green business? Harvard Bus. Rev., 80(6), 28-29.

Shridharan, L. and Manimala, M.J. (1999). Promoting industrial clusters: Review of experiences in Europe, East Asia and India. J. Entrepreneurship, 8(2), 165-193.

Storper, M. and Harrison B. (1991). Flexibility, hierarchy and regional development: The changing structure of industrial production system and their forms of governance in the 1980s. Res. Pol., 20, 407-422.

van den Bergh and Verbruggen (1999). Spatial sustainability, trade and indicators: an evaluation of 'environmental footprint'. Ecolog. Econ., 29, 61-72.

Veleva, V., Hart, M., Greiner, T. and Crumbley, C. (2001). Indicators of sustainable production. J. Clean. Prod., 9, 447-452.

Wackernagel, M. and Rees, W. (1996). Our Ecological Footprint, New Society, Philadelphia, PA, USA.

WEF (2001). 2001 Environmental Sustainability Index, Annual Meeting Report, Davos, Switzerland. 